TITLE:

\title{
Effects of sex control and twinning on economic optimization of culling cows in Japanese Black cow-calf production systems.
}

$\operatorname{AUTHOR}(\mathrm{S})$ :

Oishi, K; Hirooka, H

\section{CITATION:}

Oishi, $K$... [et al]. Effects of sex control and twinning on economic optimization of culling cows in Japanese Black cow-calf production systems.. Theriogenology 2012, 77(2): 320330

ISSUE DATE:

2012-01-15

URL:

http://hdl.handle.net/2433/153018

\section{RIGHT:}

(C) 2012 Elsevier Inc:; This is not the published version. Please cite only the published version.; この論文は出版社版でありません。引用の際に は出版社版をご確認ご利用ください。 
Effects of sex control and twinning on economic optimization of culling cows in

Japanese Black cow-calf production systems

5

\section{Kazato Oishi* and Hiroyuki Hirooka}

7

Laboratory of Animal Husbandry Resources, Division of Applied Biosciences,

Graduate School of Agriculture, Kyoto University, 6068502 Kyoto, Japan

E-mail:

Kazato OISHI: kazato@kais.kyoto-u.ac.jp

Hiroyuki HIROOKA: hirooka@kais.kyoto-u.ac.jp

*Corresponding author: Kazato OISHI

Tel\&Fax: +81-75-753-6365

E-mail: kazato@kais.kyoto-u.ac.jp

Laboratory of Animal Husbandry Resources, Division of Applied Biosciences,

Graduate School of Agriculture, Kyoto University,

Kitasirakawa-Oiwake-Cho, Sakyo-ku, Kyoto 606-8502, Japan 


\section{Abstract}

The effects of sex control and twinning techniques on determination of optimal culling parity of cows in beef cow-calf production systems were deterministically analyzed using a herd model simulation. The model simulated the annualized net revenue as an economic indicator during the whole life cycle of a cow. Biological factors (survivability, growth, reproduction, and feed requirements) and economic factors (returns from sales of live calves and cows' carcasses and production costs) were included in the model. Some biological and economic parameters relating to these factors were altered from a base condition in order to adapt the production systems with sex control and twinning techniques. The results indicated that early culling was optimal for all production systems when biological efficiency was used as an indicator of production; however, later culling was optimal for single production, but slightly earlier culling was optimal for twin production, when the annualized net revenue was evaluated. The introduction of sex control did not greatly affect the determination of the optimal culling parity of cows. In the production that included the sex control technique, female sexing increased biological efficiency whereas male sexing increased the annualized net revenue. In the present beef cow-calf production circumstances in Japan, introduction of sex control did not have economically appreciable effects, but twinning was economically beneficial. For production involving the sex control, improvement in the conception rate per mating and/or reduction of the technical cost were required for use of this technology to be profitable.

Key words: beef cow-calf production, annualized net revenue, optimal culling parity, sex control, twinning 


\section{Introduction}

At present, there are potential uses for new reproductive techniques in the beef industry. It is known that, among such techniques, sexing and twinning can have the potential to improve the efficiency of beef production [1]. Nevertheless, such new techniques do not always result in the enhancement of overall economic efficiency due to low reproductive performance, high mortality and high production costs, and therefore should be carefully evaluated before implementation [2].

Obtaining more offspring of a favored sex by the use of sexed semen has long been expected to become prominent in livestock industries for which the sex of the animals is an economically important trait [3]. However, the use of sexed semen negatively affects the conception rate, which was found to be only 70 to $80 \%$ as great as with conventional semen for heifers and cows [4]. This reduction of the conception rate can be an economic risk associated with the sex control technique.

Twinning in beef cattle potentially provides an opportunity to increase economic efficiency of beef production [5]. However, productivity is not directly proportional to the number of calves born because twins have lower body weights at birth and weaning rather than singles [6]. Moreover, higher incidences of fetal and pre-weaning calf mortality can cause the loss of the potential economic gains from twinning in cattle $[7]$.

Although some studies have documented the economic impacts of introducing sex control $[8-10]$ or twinning $[2,5,11]$ in dairy or beef production, the culling cow age was fixed or its effect was ignored in most of the analyses. However, the parity of cows can affect some key elements related to the efficiency of cow-calf production such as the conception rate of cows and the weaning weight of their calves [12], indicating that the effect of the parity of cows in culling strategy can be an important trigger for herd 
1 economics. Therefore, the effects of sex control and twinning techniques on biological and economic efficiencies of cow-calf production should be evaluated by taking the differences in culling strategies into account.

The objectives of this study were to evaluate the effects of sex control and twinning techniques on determination of optimal cow culling strategies and to analyze the effects of biological and economic parameters on annualized net revenue (an economic indicator) in Japanese Black cow-calf production systems.

\section{Materials and methods}

\subsection{General}

The biological and economic outputs of Japanese beef cow-calf production systems were simulated at the herd level. The base production system without sex control and twinning techniques (Base) and five alternatives that included such techniques were evaluated by the simulation model: the production system with male sexing (Male-S), the production system with female sexing (Female-S), the production system with twinning $(\mathrm{T})$, the production system combining twinning and male sexing (Male-S+T), and the production system combining twinning and female sexing (Female-S+T).

\subsection{Base production system}

The model used in this study was based on the model described by Oishi et al [13]. The default values of the biological and economic parameters in this study are presented in Table 1. The variables for nutrition and management were chosen to represent typical beef cow-calf production system in Japan [14]. The annualized net revenue was adopted as an economic indicator over the whole life cycle of a cow. All simulations were conducted deterministically based on a one-day time step.

Mortality was considered in two cases: pre-weaning calf mortality and annual 
1 cow mortality. Birth and mature weights were set as fixed parameters. The

2 weaning weight of calves was assumed to be expressed as a quadratic function of

3 the parity of their dams [13]. The birth, weaning and mature body weights of steers

4 were expressed as 1.2, 1.08 and 1.2 times those of heifers, respectively. Body

5 weight changes in each sex were estimated from the growth curves, which were represented by straight lines from birth to weaning and by Brody's curve [15] from weaning to culling. For pregnant cows, the total weight of the conceptus was added to the maternal weight in the last 2 months of pregnancy [16]. The conception rates of cows by parity were calculated from a quadratic function of the number of parity using the data of Rogers [17]. The effect of feeding level on conception rate was not considered, because sufficient feed was assumed to be given. Mating trial times were fixed for each reproduction cycle [18]. The calving rate of cows was determined by calf losses considering the effects of abortions and of fetal and perinatal death. The replaced heifers that failed to conceive after the given mating trials were assumed to be culled immediately, and those which failed to deliver were culled at calving. If breeding cows failed to conceive and deliver, they were assumed to be culled when their calves were weaned. Daily milk yields of cows were estimated using Wood's lactation curve [19]. The metabolizable energy (ME) requirement was estimated based on Japanese feeding standards for beef cattle [13,14] and AFRC [16]. The supplemented ME of calves was assumed to be from dietary feed in this study when ME intake from the dam's milk was not sufficient for the ME requirements of calves. The sub-model was modified in this study so that it could readily apply to the twinning systems in which a large deficit of milk energy from a cow occurs for the cow's pre-weaning calves (see Appendix).

The carcass price of a culled cow in each parity was predicted by the quadratic 
1 equation with a given fixed beef marbling standard (BMS) number [13]. The default

2 values for the female calf price per body weight (yen/ $\mathrm{kg}$ ) and the relative calf price

3 ratio of live male to live female were derived from MAFF [20]. The feed cost and

4 the technical costs for mating (AI semen cost and other veterinary costs per estrous

5 cycle) were incorporated in the model [13]. The other costs per day per calf

6 including managerial costs and machinery costs were based on MAFF [21].

\subsection{Sex control and twinning systems}

To evaluate the introduction of sex control and twinning techniques into the base production system, some base parameters were altered (Table 2). When twinning and sex control techniques were combined, the rates of change in the parameters from each option were multiplied.

For sex control systems, the conception rates with a dose of sexed sperm for heifers and cows were as high as $80 \%$ of conventional conception rates due to the damage that occurs during the sexing process and the use of fewer sperm per dose [22-24]. Sexing accuracy was set to be $90 \%[9,25,26]$. For the production systems with male sexing (Male-S and Male-S+T), it was assumed that female sexing be conducted only in the $1^{\text {st }}$ reproduction cycle to keep the fixed number of replacement female calves for the purpose of maintenance of the cow population. The AI cost of sexed sperm was assumed to be about 30 dollars $(¥ 3,000)$ higher than that of the conventional unsexed system (Base) as the additional premium cost for cell sorting technology $[3,27]$.

For the twinning systems, the mean values of unilateral and bilateral twin ovulation in the literature were adopted. The birth and weaning weights of each of the twin calves were assumed to be 18.8 and $14.1 \%$ smaller than singles, respectively [28]. The conception rates for twins and singles were assumed to be the same as in Echternkamp et al [29], while the calving rate and the pre-weaning survivability for twins were set to 
1 be lower than singles [28,30]. Gestation length was 6.8 days $(2.4 \%)$ shorter for twins

2 [28]. The total annual milk yield of cows was assumed to be about $25 \%$ higher for

3 twin-bearing cows than for single-bearing cows $[5,6]$. Technical costs per calf,

4 including AI cost, ET cost and other veterinary and labor costs, were assumed to be

$540 \%$ higher for twins because of the high incidence of dystocia that resulted primarily

6 from malpresentation [5]. The sex ratio of calves at birth was assumed to be identical

7 between single and twin births.

The herd composition dynamics of the model included three animal categories: male calves, non-replacement female calves, and replacement heifers and cows [13]. Self-replacement production was assumed through this study, and therefore it was necessary to control the replacement rate of cows to maintain the herd size with the changes in sex ratio and the planned culling parity of cows. This control function is as follows:

$$
\operatorname{rep}(p a)=1 / \sum_{i=1}^{p a}((1-\operatorname{Rsex}(i)) \times N e w b(i))
$$

where $\operatorname{rep}(p a)$ is the replacement rate of cows determined by the variable $p a$ that indicates the number of the planned culling parity, Rsex(i) is the controlled sex ratio as the proportion of males at reproduction time $i$ and $N e w b(i)$ is the number of newborns at reproduction time $i$. In twinning systems, the effect of freemartin was considered in this study: only females born as all female co-twins $(25 \%$ of the total twin births) were assumed to be fertile and used for replacement in this study [30]. Individual production traits were multiplied by the animal numbers of the herd components which were derived from the replacement rate function.

\subsection{Evaluation of production systems}

The effects of the culling parity of cows on biological efficiency (total weight output 
1 of live calves and culled cows ( $\mathrm{kg}$ ) / total ME intake (GJ)) and the annualized net

2 revenue were examined in the Base and alternative production systems. The planned

3 culling parity showing the highest annualized net revenue can be regarded as the

4 optimal targeted herd life. The annualized net revenue is calculated based on Meadows

5 et al $[31]$ as

$$
\begin{aligned}
& N P V(p a)=\sum_{i=0}^{\operatorname{Day}(p a)}\left(C F(i) /(1+d r)^{i}\right) \\
& E D C(p a)=N P V(p a) \times d r /\left(1-\left(1 /(1+d r)^{\operatorname{Day}(p a)}\right)\right. \\
& A N(p a)=E D C(p a) \times 365
\end{aligned}
$$

where $N P V(p a)$ is the net present value associated with keeping a cow until parity $p a, \operatorname{Day}(p a)$ is the number of planning days until parity $p a, C F(i)$ is the daily cash flow, $d r$ is the daily discount rate, $E D C(p a)$ is the equivalent daily cash flow associated with keeping a cow until parity $p a$, and $A N(p a)$ is the annualized net revenue (or the estimated equivalent annuity). The daily cash flow is defined as the daily return (estimated only in cases where calves or beef from culled cows are sold) minus daily cost (including feed cost, AI cost and other fixed cost) for cows of age $i$ in days and their calves. The daily discount rate is calculated from the annual discount rate as: $d r=\sqrt[365]{(1+y d r)}-1$ where $y d r$ is the annual discount rate. The annual discount rate in this study was assumed to be $5 \%$.

\section{Results}

Fig. 1 shows the biological efficiency and the annualized net revenue with the change in the planned culling parity of cows under the six production systems. The culling parity with the highest biological efficiency was $3^{\text {rd }}$ parity for all production systems. Note that planned culling parities from the third to the twelfth were simulated 
1 because the herd in the Base system cannot maintain the initial number of cows with only home-bred replacement heifers when reproduction occurs less than three times per cow.

The biological efficiencies in all production systems with the twinning technique were higher than those in the single production systems. The production systems with female sexing had higher biological efficiency than the production systems with male sexing in both single and twin production. On the other hand, the optimal culling parity with the highest annualized net revenue differed between single and twin production systems, being the $8^{\text {th }}$ parity for single production systems and the $5^{\text {th }}$ to $6^{\text {th }}$ parity for twin production systems. Moreover, the order of production systems in terms of their annualized net revenue was considerably different compared to that in terms of their biological efficiency. The annualized net revenue in the Twin system was slightly higher than in the Base system until the $6^{\text {th }}$ parity at culling, but the production systems combining twining and sex control techniques (Male-S+T and Female-S+T) had lower annualized net revenue than the Base system. The production systems with female sexing (Female-S and Female-S+T) had markedly lower annualized net revenue than those with male sexing (Male-S and Male-S+T), and the annualized net revenue in the sex control systems was lower than in the production systems without the sexing technique. Decreases in the annualized net revenue occurring in later parity in all production systems were caused by decreases in the conception rate of the cows and the weaning weight of their calves.

The effects of female calf price on the economically optimal culling parity of cows in the six production systems are presented in Fig. 2. The optimal culling parity was highly sensitive to female calf price in all production systems. The optimal culling parity increased consistently with female calf price in all production systems, but the 
1 increase in the twin production systems was lower than in the single production systems. When the female calf price was $750(¥ / \mathrm{kg})$, the optimal culling parity was the $3^{\text {rd }}$ for all production systems, but when the female calf price $\geq 1,250(¥ / \mathrm{kg})$, the optimal culling parity for single production was fixed at the $8^{\text {th }}$ to $9^{\text {th }}$ parity and that for twin production was the $5^{\text {th }}$ to $6^{\text {th }}$ parity. In contrast, sex control did not greatly affect the optimal culling parity.

When the culling parity of cows was set to the optimal parity in single production systems (the $8^{\text {th }}$ parity with the female calf price $=1,250(¥ / \mathrm{kg})$ ), small increases in the conception rate and relative calf price ratio (expressed as the ratio of live male price to live female price) and a small decrease in the technical cost can make the Male-S system more beneficial than the Base system as shown in Fig. 3. About a $3 \%$ improvement of the conception rate or a $9 \%$ reduction of the technical cost were needed to achieve the same level of the annualized net revenue in the Male-S system compared to that in the Base system.

The difference between the annualized net revenues of the Male-S and Female-S systems was used to evaluate the advantage of male sexing over female sexing (Fig. 4). The threshold values of the relative calf price ratio for selecting male or female sexing increased with a decrease in female calf price. However, even if the female calf price was $60 \%$ of the present female calf price, the Male-S system became more beneficial than the Female-S when only a $6 \%$ difference in calf price existed between live males and live females.

Fig. 5 shows the sensitivity of the annualized net revenue to changes in the biological parameters (weights at birth and weaning, calving rate, pre-weaning survivability, gestation length and annual milk yield) and the technical cost in the Twin system under the optimal culling parity of cows (the $5^{\text {th }}$ parity with the female calf 
1 price $=1,250(¥ / \mathrm{kg}))$. The annualized net revenue was sensitive to changes in all

\section{Discussion}

\subsection{Biological efficiency}

The biological efficiency of the single production systems (Base, Male-S and Female-S) decreased consistently with increasing culling parity, a result that was similar to the results reported elsewhere $[1,32,33]$. The biological efficiency of the single production systems was highest in the production system with female sexing and lowest in the system with male sexing. This result might be due to the difference in the amount of ME derived from dietary feed between male and female pre-weaning calves; male calves having greater body weights required more ME from supplemented feed compared to female calves, since the ME from the dam's milk was limited (see Appendix). The biological efficiencies in the twin production systems were always higher than in single production systems; a remarkable increase in the number of calves produced with twinning can improve biological efficiency despite the negative effects of the technique on several biological aspects (e.g. smaller weight, lower calving rate, higher pre-weaning mortality and higher requirements of dietary feed for calves), as was expected by some researchers [7,34]. 


\subsection{Optimal culling parity with the highest annualized net revenue}

The optimal culling parity showing the highest annualized net revenue was different between the single and twin production systems when the female calf price was set to $1,250(¥ / \mathrm{kg})$. In our previous study of the base production system [13], the annualized net revenue increased until the $8^{\text {th }}$ to $9^{\text {th }}$ parity. This was consistent with the results for the systems involving the single sex control technique (Male-S and Female-S), although the mating times were different between the previous and present studies. In general, the culling of cows later in their lifetime may occur when the sales price of calves is expected to be high compared to that of culled dams. For commercial beef cow-calf production in the US, Melton et al [35] reported that an increase in the culled cow price relative to the calf price results in cow culling at an earlier age. Bourdon and Brinks [33] concluded that the optimal age of cows at culling has a negative relationship with the price of culled cows relative to the price of their calves. This study assumed a decrease in the price of culled cows with an increase in the parity of culling based on local farm carcass data in Japan, and the mean price of culled cows from the $3^{\text {rd }}$ to $12^{\text {th }}$ parity of culling was $950(¥ / \mathrm{kg})$. Therefore, except for the production system involving both twinning and male sexing (Male-S+T), economically optimal culling occurred at an early stage when the price of culled cows relative to the price of their live female calves was nearly equal to 1 (Fig. 2).

The introduction of the sex control had no influence on the determination of optimal culling parity despite the decrease in the conception rate. This might be because a single service conception rate was used in this study, and therefore multiple mating trials could reduce the negative effect of the decrease in conception rate on the number of calves produced. On the other hand, the optimal 
1 culling parity in twin production systems occurred earlier than in single production systems due to the lower calving rate in twin production systems. The low calving rate in twin production systems decreased the number of cows in later parities, reduced the optimal culling parity, and reduced the expected economic advantage of twinning.

When genetic performance of animals under breeding schemes is incorporated in the model to consider genetic progress, the optimum culling parity may differ from the present results. Ollivier [36] pointed out that earlier culling of breeding animals is generally advisable because of the shorter generation interval from a genetic point of view, but in some cases, an increase in generation length can be recommended to take advantage of the increase in accuracy of selection resulting from increased records from the progenies. However, since this study focused on the economic optimization for commercial beef cow-calf production systems, no attempt was made to evaluate genetic aspects of culling strategies.

\subsection{Economic potential of the sex control technique}

Comparisons of the annualized net revenue between the sexing systems and the Base system indicated that the Male-S system became more profitable than the Base system when either conception rate or the technical cost per calf was improved by only a few percentage points (Fig.3). As for the conception rate, the Male-S system produced higher annualized net revenue than the Base system when the conception rate was higher than $82.6 \%$ of that in the Base condition. Recent improvements in sorting and cryopreservation procedures have improved the fertility of sexed sperm and pregnancy rates could achieve $90 \%$ of conventional pregnancy rates in well-managed heifers [9]. This means that a male sexing system is now technically possible and is the most beneficial single production system. 
1 Moreover, the conception risk when using sexed semen in dairy cows can be at the same level as that for conventional semen when the cows have completely normal reproductive function [23]. These indicate that enhancement of the conception rate can be achieved in sex control systems. Furthermore, the additional premium for sexing sperm had to be less than $15.9 \%$ of the technical cost $(¥ 1,908)$ assumed in our study. However, additional costs reported at approximately 30 dollars $[3,27]$ would be expected to decrease with increased adoption of sexing technology. In addition, the results of this study indicated the importance of the relative calf price ratio of live male to live female in the use of sex control in Japanese cow-calf production systems (Fig. 4). An increase of less than $2 \%$ in the ratio can lead the Male-S system to have higher annualized net revenue than the Base system. The ratio also affected the choice of male or female sexing, and the threshold value for the ratio was lower than 1.04 in the situation where the female calf price was nearly equal to the carcass price of culled cows $(950(¥ / \mathrm{kg}))$ in this study (Fig. 4). The ratio was set to be 1.134 (13.4\% higher price for male calves) in this study and was reported as about 1.073 in the US [37] and 1.067 in Ireland [38]. Therefore, it can be concluded that male sexing is usually more economically valuable than female sexing in beef cow-calf production when the herd size is fixed, although calf market conditions may be highly changeable among seasons and regions.

\subsection{Economic potential of the twinning technique}

In the present circumstances, the production system with the twinning technique can be considered to be slightly economically beneficial compared to the Base production system despite the negative impacts on some production traits and the additional supplementation of dietary feed for pre-weaning calves (Fig. 1). Furthermore, the sensitivity analysis indicated that the improvement of the calving rate and pre-weaning 
1 survivability could greatly increase the economic benefit (Fig. 5). As for the calving rate, an improvement of this rate in twin production could increase the annualized net revenue and also increase the optimal culling parity (Fig. 6). With a $10 \%$ improvement of the rate of change in the calving rate, the annualized net revenue could be increased by $80.9 \%$ with culling at $5^{\text {th }}$ parity, which was the optimal culling parity for the base twin production, and moreover, could be increased by $89.6 \%$ by changing the culling parity to the $7^{\text {th }}$ parity, which was the optimal culling parity for the improved production system. These analyses stressed the importance of improving the calving rate by decreasing the calf losses caused by twinning. In contrast, the change in the technical cost on the annualized net revenue was relatively small in this study (Fig.5). However, it is noted that when the cost for twinning technique is extremely high, the beneficial effect of twinning technique will be negated.

A few studies on the economic consequences of the introduction of the twinning technique in beef production have been reported, although many studies have examined the biological impacts of twinning [e.g. 28,29,34,39]. Herd et al [2] stated that, based on gross margin estimation, yearling beef production using the twinning technique was more profitable than traditional production systems in Australia, which was in agreement with results of the present study. Guerra-Martinez et al [5] concluded that the estimated herd input costs per unit of beef output was $24 \%$ lower for twin than for single births, but the study simply treated the marketed weights as the beef output. In addition, to our knowledge, there have been no reports that have analyzed the sensitivity of detailed economic measures (such as the annualized net revenue) to the changes in biological and economic parameters in beef production systems in which the twinning technique has been introduced. Therefore, the results of this study could provide valuable economic information for beef cow-calf production systems that 
1 incorporate the twinning technique.

2

3

4

\section{Conclusions}

This study determined the effects of introducing sex control and twinning on the optimal culling parity of cows. Culling parity with the highest biological efficiency was the same for all production systems ( $3^{\text {rd }}$ parity), whereas the optimal culling parity with the highest annualized net revenue differed between single and twin production systems $\left(8^{\text {th }}\right.$ parity and $5^{\text {th }}$ to $6^{\text {th }}$ parity, respectively). Sex control did not greatly affect the culling parity of cows to optimize annualized net revenue; however female sexing increased biological efficiency whereas male sexing increased annualized net revenue. The economic value of sex control in beef cow-calf production systems was dependent upon improved conception rate per mating and/or reduction of the technical cost. Twinning was beneficial in present beef cow-calf production systems, and the economic value greatly increased with improvements of the calving rate.

\section{References}

[1] Taylor $\mathrm{S}_{\mathrm{T}}$ CS, Moore JA, Thiessen RB, Bailey CM. Efficiency of food utilization in traditional and sex-controlled systems of beef production. Anim Prod 1985;40:401-40.

[2] Herd RM, Bootle BW, Parfett DC. An economic evaluation of traditional, twining and sex-controlled systems of beef production in Southern Australia. Australian J Agric Res 1993;44:1541-56.

[3] Olynk NJ, Wolf CA. 2007. Expected net present value of pure and mixed sexed semen artificial insemination strategies in dairy heifers. J Dairy Sci 
[4] Norman HD, Hutchison JL, Miller RH. Use of sexed semen and its effect on conception rate, calf sex, dystocia, and stillbirth of Holsteins in the United States. J Dairy Sci 2010;93:3880-90.

[5] Guerra-Martinez P, Dickerson GE, Anderson GB, Green RD. Embryo-transfer twinning and performance efficiency in beef production. J Anim Sci 1990;68:4039-50.

[6] De Rose EP, Wilton JW. Productivity and profitability of twin births in beef cattle. J Anim Sci 1991;69:3085-93.

[7] Echternkamp SE, Gregory KE. 1999. Effects of twinning on postpartum

[8] Hohenboken WD. Applications of sexed semen in cattle production. Theriogenology 1999;52:1421-33.

[9] Seidel Jr. GE. Economics of selecting for sex: the most important genetic trait. Theriogenology 2003;59:585-98.

[10] Madalena FE, Junqueira FS. 2004. The value of sexed bovine semen. J Anim Breed Genet 2004;121:253-9.

[11] Eddy RG, Davies O, David C. An economic assessment of twin births in British dairy herds. Vet Rec 1991;129:526-9.

[12] Renquist BJ, Oltjen JW, Sainz RD, Calvert CC. Effects of age on body condition and production parameters of multiparous beef cows. J Anim Sci 2006;84:1890-5.

[13] Oishi K, Ibi T, Kahi AK, Hirooka H. Optimal culling strategy in relation to biological and economic efficiency and annualized net revenue in the Japanese 
Black cow-calf production system. J Agric Sci 2011;149:783-799.

[14] National Agriculture and Food Research Organization (NARO). Japanese feeding standard for beef cattle. National Agriculture and Food Research Organization, Central Association of Livestock Industry, Tokyo. 2009. (In Japanese)

[15] Brody S. Bioenergetics and Growth. Reinhold Publishing Corporation, New York. 1945.

[16] Agricultural and Food Research Council (AFRC). Energy and Protein Requirements of Ruminants. An advisory manual prepared by the Agricultural and Food Research Council Technical Committee on Responses to Nutrients. CAB International, Wallingford. 1993.

[17] Rogers LeRoy F. Economics of replacement rates in commercial beef herds. J Anim Sci 1972;34:921-5

[18] Hirooka H, Groen AF, Hillers J. Developing breeding objectives for beef cattle production. 1. A bio-economic simulation model. Anim Sci 1998;66:607-21.

[19] Wood PDP. Algebraic model of the lactation in cattle. Nature 1967;216:164-5.

[20] Ministry of Agriculture, Forestry and Fisheries of Japan (MAFF). The change in average price of beef calves. Livestock Industry Department, Agricultural Production Bureau, Ministry of Agriculture, Forestry and Fisheries of Japan, Tokyo. 2008. (In Japanese)

[21] Ministry of Agriculture, Forestry and Fisheries of Japan (MAFF). Statistics of agriculture, forestry and fisheries. Statistics division of the Ministry of Agriculture, Forestry and Fisheries of Japan, Tokyo. 2009. (In Japanese)

[22] Garner DL, Seidel Jr GE. History of commercializing sexed semen for cattle. 
$1 \quad$ Theriogenology 2008;69:886-95.

2 [23] Seidel Jr GE. Overview of sexing sperm. Theriogenology 2007;68:443-6.

3 [24] Weigel KA. 2004. Exploring the role of sexed semen in dairy production systems. J Dairy Sci 2004;87:E120-30.

[25] De Jarnette JM, Nebel RL, Marshall CE, Moreno JF, McCleary CR, Lenz RW. Effect of sex-sorted sperm dosage on conception rates in Holstein heifers and lactating cows. J Dairy Sci 2008;91:1778-85.

[26] Tubman LM, Brink Z, Suh TK, Seidel Jr GE. Characteristics of calves produced with sperm sexed by flow cytometry / cell sorting. J Anim Sci 2004;82:1029-36.

[27] De Vries A. Sexed semen economics. Proc $45^{\text {th }}$ Florida Dairy Prod Conf, Gainesville 2008;67-82.

[28] Echternkamp SE, Thallman RM, Cushman RA, Allan MF, Gregory KE. Increased calf production in cattle selected for twin ovulations. J Anim Sci $2007 a ; 85: 3239-48$.

[29] Echternkamp SE, Thallman RM, Cushman RA, Allan MF, Gregory KE. Effects of ovulation rate and fetal number on fertility in twin-producing cattle. J Anim Sci $2007 b ; 85: 3228-38$.

[30] Gregory KE, Echternkamp SE, Cundiff LV. Effects of twinning on dystocia, calf survival, calf growth, carcass traits and cow productivity. J Anim Sci $1996 ; 74: 1223-33$.

[31] Meadows C, Rajala-Schultz PJ, Frazer GS. A spreadsheet-based model demonstrating the nonuniform economic effects of varying reproductive performance in Ohio dairy herds. J Dairy Sci 2005;88:1244-54.

[32] Baptist R. Derivation of steady-state herd productivity. Agric Sys 
$1992 ; 39: 253-72$.

2 [33] Bourdon RM, Brinks JS. Simulated efficiency of range beef production. III. Culling strategies and nontraditional management systems. J Anim Sci $1987 ; 65: 963-9$

[34] Echternkamp SE, Gregory KE. Reproductive, growth, feedlot, and carcass traits of twin vs single births in cattle. Journal of Animal Science 2002;80:E64-73.

[36] Ollivier L. Optimum replacement rates in animal breeding. Anim Prod 1974; $19: 257-271$.

[37] Stockton MC, Besseler DA, Wilson RK. Price discovery in Nebraska cattle markets. J Agric Appl Econ 2010;42:1-14. Edition updated. National Academy Press, Washington, DC. 2000. 


\section{Appendix}

2 Estimation of energy intake from dietary feed for pre-weaning calves

3 In this study, the energy requirements of calves were assumed to be supplied only by

4 their cow's milk from birth to 30 days of age and, thereafter, both cow's milk and

5 dietary feed supplementation were assumed to provide energy resources until the

6 weaning age. It was also assumed that the cow's milk was completely consumed and

7 that deficiencies in meeting energy requirements were made up for by dietary

8 supplemented feed. The ME requirement from dietary feed was estimated from the

9 differences between the net energy requirements of all calves born from a cow and the net energy contained in the milk produced by the cow.

The expressions for converting ME values to the net energy required for maintenance (NEm, MJ/kgDM) and for growth (NEg, MJ/kgDM) are given by the $\mathrm{NRC}[40]$ as:

$$
\begin{aligned}
& N E m=1.38(M E / c j)-0.138(M E / c j)^{2}+0.0105(M E / c j)^{3}-1.12 \\
& N E g=1.42(M E / c j)-0.174(M E / c j)^{2}+0.0122(M E / c j)^{3}-1.65
\end{aligned}
$$

where $c j$ is a coefficient of unit conversion from calories to joules $(c j=4.184)$, and $\mathrm{ME}$ is the ME value of dietary feed for pre-weaning calves $(=18.4 \times q \mathrm{MJ} / \mathrm{kgDM}$ where $q$ is the metabolizability of dietary supplemented feed). Thus, the efficiencies of the utilization of ME for maintenance $\left(k_{m}\right)$ and growth $\left(k_{g}\right)$ are expressed as:

$$
\begin{aligned}
& k_{m}=N E m /(M E / c j) \\
& k_{g}=N E g /(M E / c j)
\end{aligned}
$$

The daily net energy requirements of calves ( $N E i_{x}, \mathrm{MJ} /$ day) are calculated as:

$$
N E i_{x}(t)=M E m_{x} \times k_{m}+N E g_{x}
$$

where the subscript $\mathrm{x}$ is the sex of the calves, $M E m_{x}$ is the metabolizable energy requirement for maintenance and $N E g_{x}$ is the net energy requirement for growth. $M E m_{x}$ (MJ/day) and $N E g_{x}(\mathrm{MJ} /$ day) are estimated according to NARO [14] as: 


$$
\begin{aligned}
& \operatorname{MEm}_{x}(t)=\left(0.1067 \times W_{x}(t)^{0.75}\right) / c j \\
& N E g_{x}(t)=\left(\left(0.008 \times W_{x}(t)^{0.75}+1.8\right) \times D G_{x}(t)\right) / c j
\end{aligned}
$$

1 where $W_{x}(t)$ and $D G_{x}(t)$ are the body weight and daily gain of calves at age $t$.

2 Here, the total net energy requirement of calves per cow (TNE(t), MJ/day) in the

3 production systems including the effects of sex control and twinning is calculated as:

$$
T N E(t)=N \operatorname{calf}(t) \times\left(\operatorname{Rsex}(i) \times N E i_{m}(t)+(1-\operatorname{Rsex}(i)) \times N E i_{f}(t)\right)
$$

4 where $N$ calf(t) is the number of calves at age $t$ including the effects of pre-weaning

5 survivability and of single production or twinning and $R \operatorname{sex}(i)$ is the controlled sex

6 ratio expressed as the proportion of males at reproduction time $i$ as presented in the

7 text. The total ME intake from dietary supplemented feed (TMEspl(t), MJ/day) of

8 calves can be expressed as:

$$
\begin{aligned}
\operatorname{TMEspl}(t)= & \left(\operatorname{MEm}_{m}(t)+N E g_{m}(t) / k_{g}\right) \times \operatorname{Rsex}(i) \\
& +\left(\operatorname{MEm}_{f}(t)+N E g_{f}(t) / k_{g}\right) \times(1-\operatorname{Rsex}(i))
\end{aligned}
$$

9 Thus, the efficiency of the ME utilization of dietary feed for maintenance and 10 production $(k m p(t))$ and its net energy value (Nespl(t), MJ/kgDM) are calculated as

11 follows:

$$
\begin{aligned}
& k m p(t)=\left(N E i_{m}(t) \times \operatorname{Rsex}(i)+N E i_{f}(t) \times(1-\operatorname{Rsex}(i))\right) / T M E s p l(t) \\
& N E s p l(t)=k m p(t) \times 18.4 \times q .
\end{aligned}
$$

If $\operatorname{TNE}(t)$ is more than the energy value of the milk produced by the cow $(\operatorname{Emilk}(t)$, $\mathrm{MJ} /$ day), which is calculated from the daily milk yield ( $\mathrm{kg} /$ day) multiplied by the energy value of a unit of milk (MJ/kg), the amount of dietary feed intake (DMspl(t), $\mathrm{kg} /$ day) can be estimated as:

$$
\operatorname{DMspl}(t)=(\operatorname{TNE}(t)-\operatorname{Emilk}(t)) / N \operatorname{Espl}(t)
$$

and if $T N E(t)$ is less than Emilk(t), then

$$
\operatorname{DMspl}(t)=0 .
$$


1 In consequence, the ME intakes of male or female calves from total dietary feed

$2\left(\operatorname{TMEspl}_{x}(t), \mathrm{MJ} /\right.$ day $)$ are calculated as:

$$
\begin{aligned}
& \operatorname{TMEspl}_{m}(t)=D M s p l(t) \times 18.4 \times q \times\left(N E i_{m}(t) \times N \operatorname{calf}(t) \times \operatorname{Rsex}(i)\right) / \operatorname{TNE}(t) \\
& \operatorname{TMEspl}_{f}(t)=D M \operatorname{Dspl}(t) \times 18.4 \times q \times\left(N E i_{f}(t) \times N \operatorname{calf}(t) \times(1-\operatorname{Rsex}(i))\right) / \operatorname{TNE}(t),
\end{aligned}
$$

3 and finally the ME intakes per calf from dietary feed for male and female calves

$4 \quad\left(\operatorname{MEspl}_{x}(t), \mathrm{MJ} /\right.$ day $)$ are calculated as:

$$
\begin{aligned}
& \operatorname{MEspl}_{m}(t)=\operatorname{TMEspl}_{m}(t) /(\operatorname{Ncalf}(t) \times \operatorname{Rsex}(i)) \\
& \operatorname{MEspl}_{f}(t)=\operatorname{TMEspl}_{f}(t) /(N \operatorname{Nalf}(t) \times(1-\operatorname{Rsex}(i)))
\end{aligned}
$$

5 
Table 1. Base input parameters of the model in this study

\begin{tabular}{lll}
\hline Parameters & Units & Default values \\
\hline Birth weight (x 1.2 for males) & $k g$ & 30 (females) \\
Mature weight (x 1.2 for males) & $k g$ & 515 (females) \\
Total annual milk yield & $k g$ & 970 \\
Wood's curve parameter for lactation $b$ & & 0.073 \\
Wood's curve parameter for lactation c & $d$ & 0.0056 \\
Anestrus postpartum interval & $d$ & 40 \\
Mean length of the estrous cycle & $n$ & 21 \\
Mating trial times & & 5 \\
Calving rate & $d$ & 0.98 \\
Gestation length & $d$ & 285 \\
Weaning age & $d$ & 150 \\
Age at first mating & & 420 \\
Pre-weaning calf mortality & & 0.02 \\
Annual mortality rate after weaning & & 0.02 \\
Dressing rate of culled cows & $d$ & 0.6135 \\
Age at calf market & & 285 \\
Overall metabolizability & & 0.6 \\
Metabolizability of concentrates & & 0.70 \\
Metabolizability of roughage & & 0.45 \\
Metabolizability of feeds for growing heifers and dry cows & & 0.53 \\
Metabolizability for dietary supplemented feed & $n$ & 3 \\
Beef marbling score of culled cows & $y e n / k g$ & 1250 \\
Live female calf price & & 1.1344 \\
Relative calf price ratio of live male to live female & $y e n / k g D M$ & 30 \\
Price of concentrates for cows (x 1.3 for roughage) & $y e n / k g D M$ & 38 \\
Price of concentrates for pre-weaning calves (x 1.3 for roughage) & $y e n / m a t i n g$ & 12000 \\
Technical cost ${ }^{1)}$ & $y e n / d$ calf & 392 \\
Other cost ${ }^{2)}$ & &
\end{tabular}

${ }^{1)}$ Includes AI cost, ET cost and other veterinary and labor costs.

${ }^{2)}$ Includes managerial costs and machinery costs. 
Table 2. Rate of change in parameters $(\%)^{1)}$ when introducing the sex control and twinning techniques

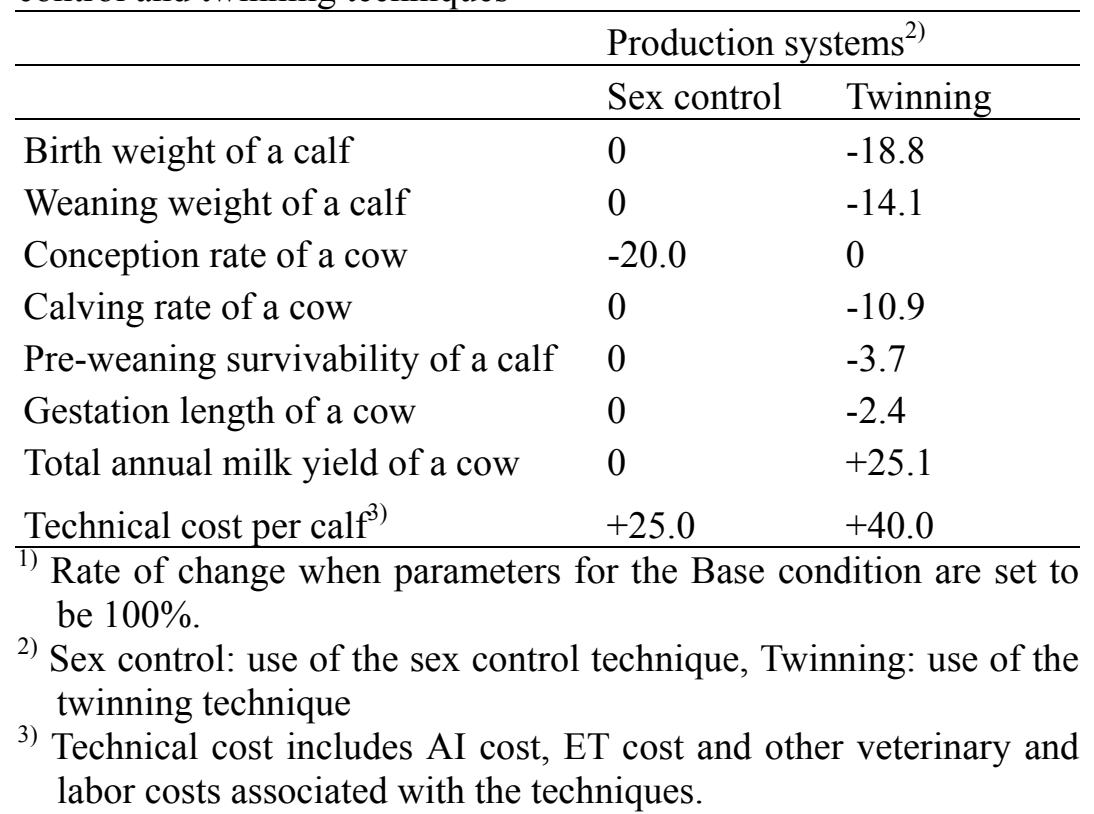


a) Biological efficiency

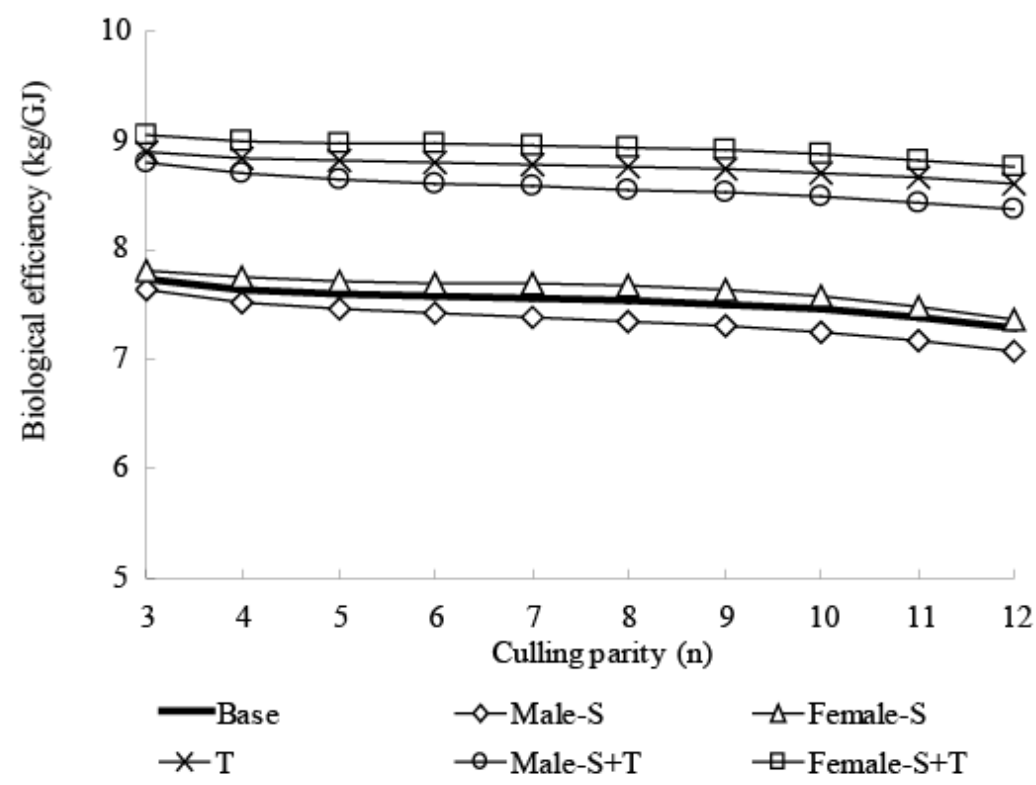

b) Annualized net revenue

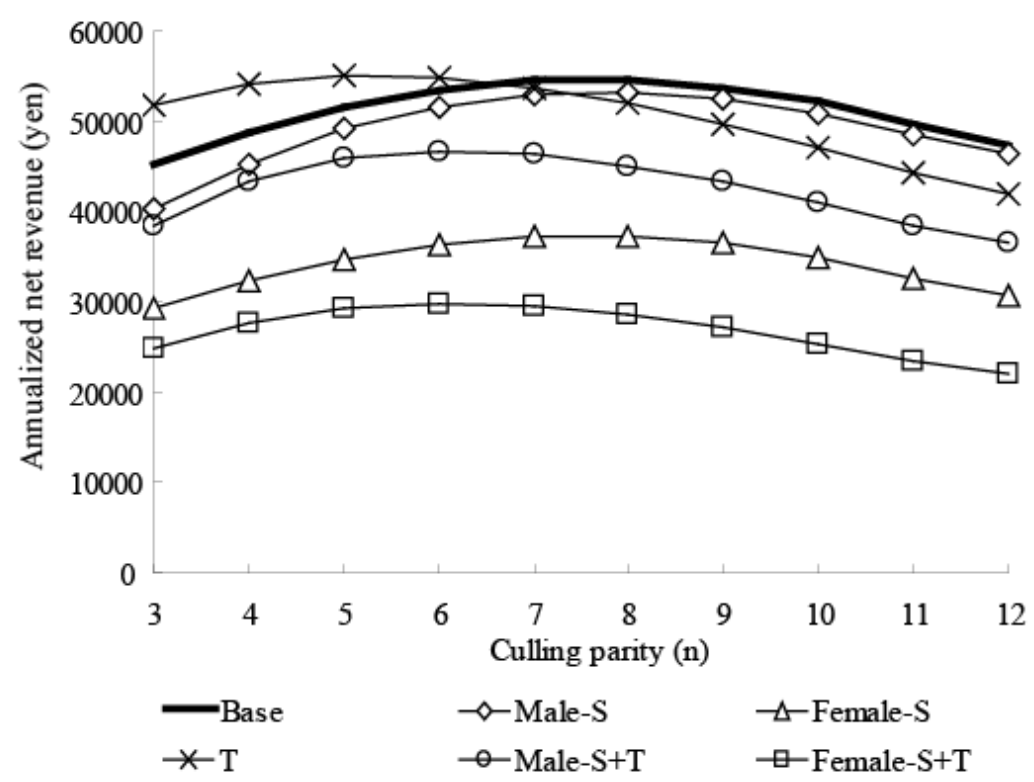

1

2 Fig. 1. Effect of the change in culling parity of cows on biological efficiency and

3 annualized net revenue in the six production systems: Base (conventional single

4 production), Male-S (with sex control technique (male sexing)), Female-S (with sex

5 control technique (female sexing)), $\mathrm{T}$ (with twinning technique), Male-S+T (with

6 twinning and sex control techniques (male sexing)), and Female-S+T (with twinning

7 and sex control techniques (female sexing)). 


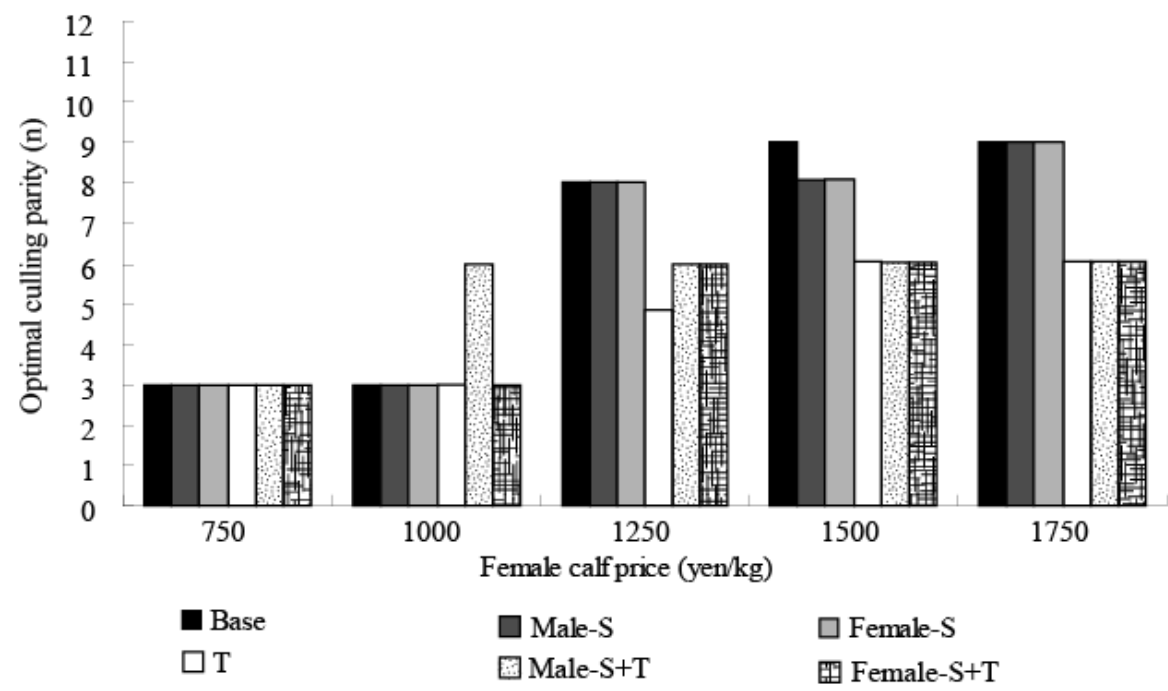

2 Fig. 2. Effect of the change in female calf price on the economically optimal culling

3 parity of cows in the six production systems ${ }^{1)} .{ }^{1)}$ See the caption of Fig. 1.

4

5 


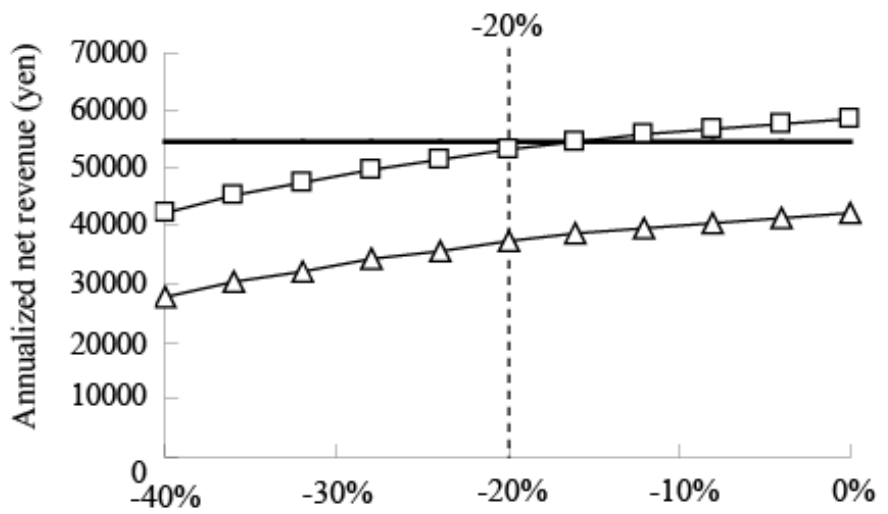

a) Rate of change in concepion rate

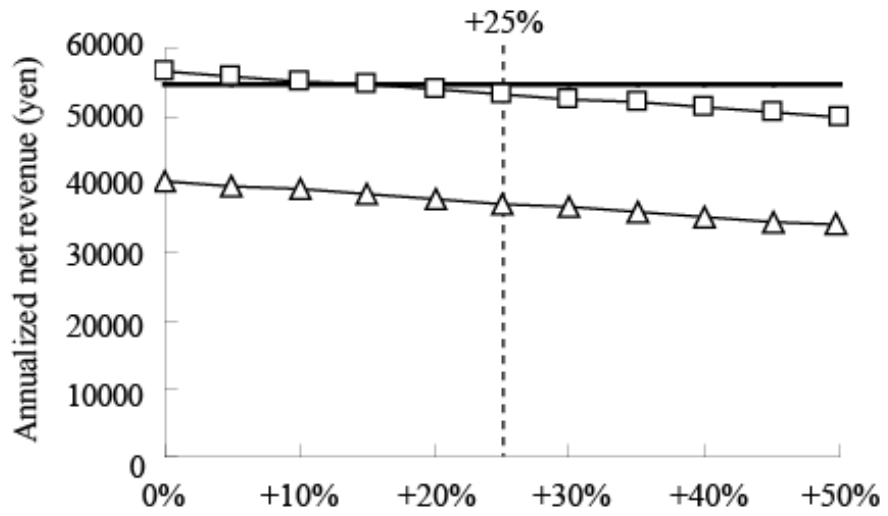

b) Rate of change in technical cost

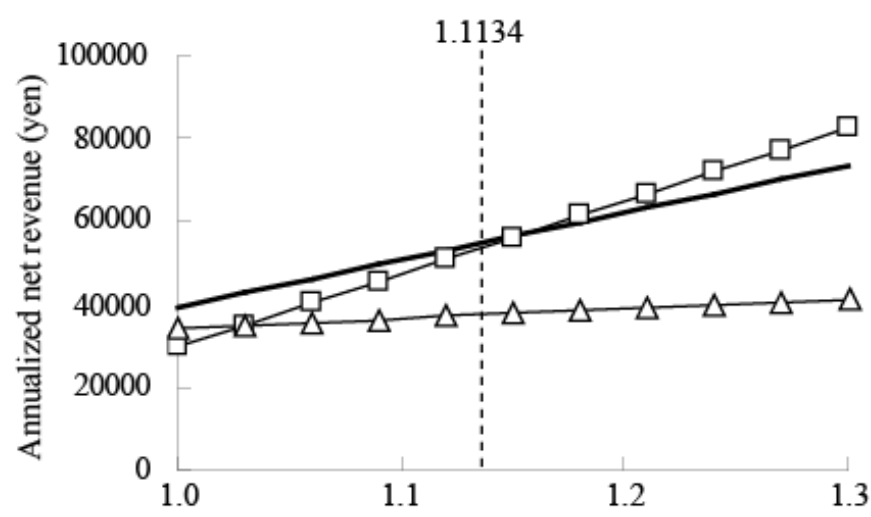

c) Relative calf price ratio of live male to live female

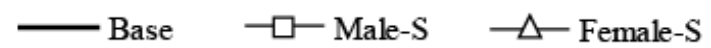

2 Fig. 3. Effects of the change in the rates of change in the conception rate (a) and the

3 technical cost (b) and the relative calf price ratio of live male to live female (c) on the

4 annualized net revenues in the production systems ${ }^{1)}$ with and without the sex control

5 technique. Break lines in the figures represent the default values of the rates. ${ }^{1)}$ See the

6 caption of Fig. 1. 


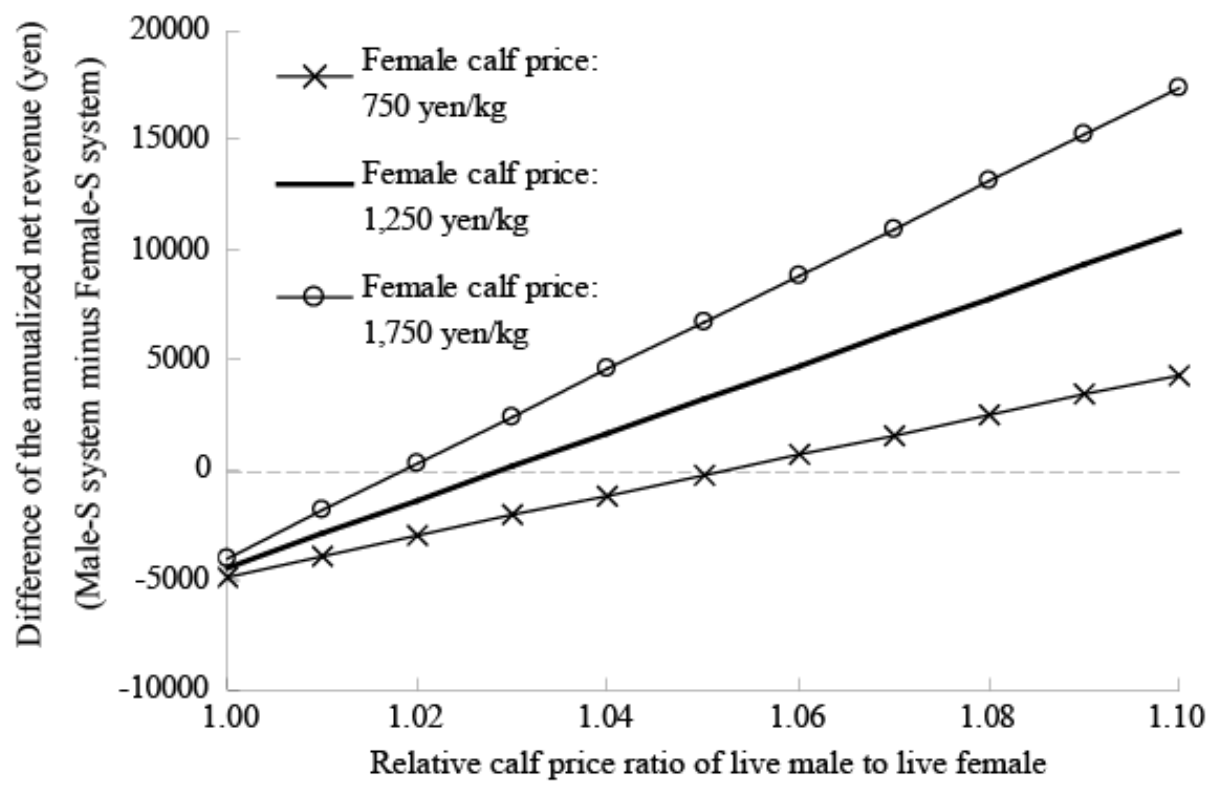

2

3 Fig. 4. Advantage of the Male-S system over the Female-S system ${ }^{1)}$ with the change in

4 the relative calf price ratio of live male to live female. The ratios when the difference

5 equals zero are the threshold values for selecting male sexing or female sexing.

$6 \quad{ }^{1)}$ See the caption of Fig. 1. 


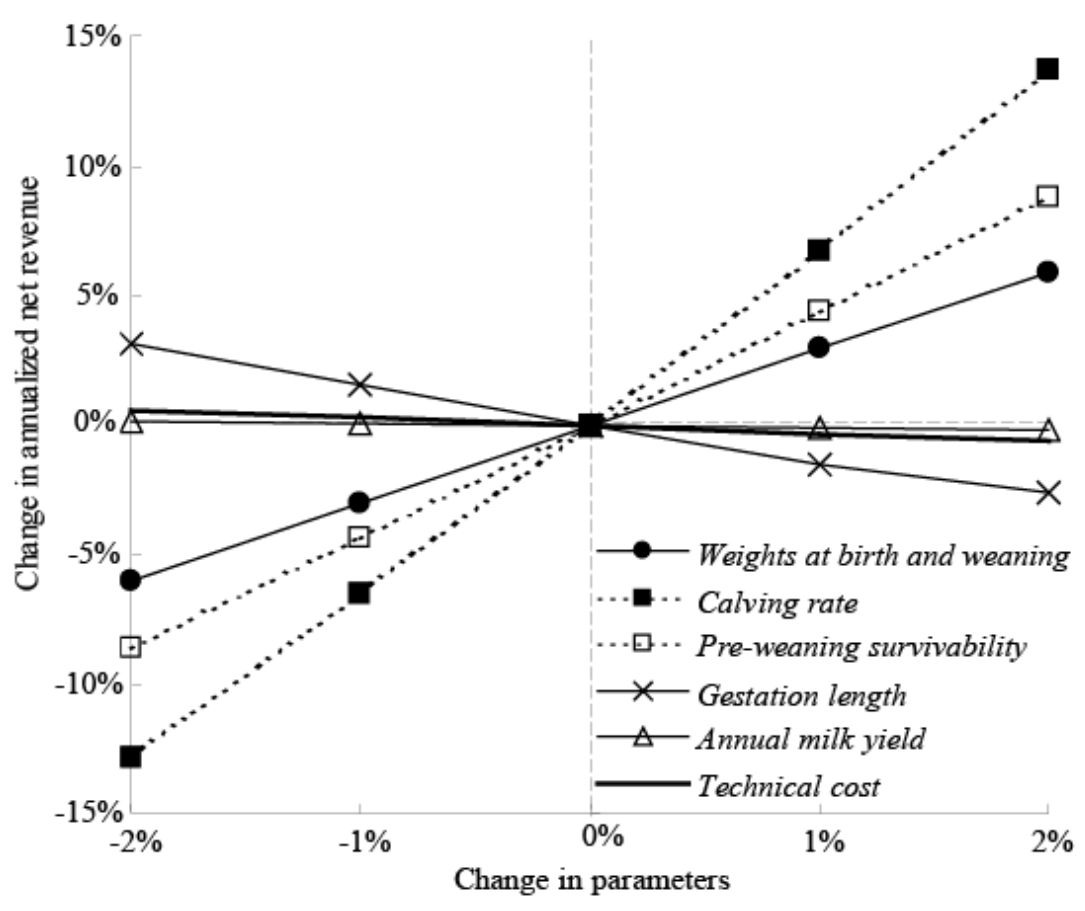

2

3 Fig. 5. Sensitivity of the annualized net revenue to changes in weights at birth and

4 weaning, calving rate, pre-weaning survivability, gestation length, annual milk yield

5 and technical cost in the production system with the twinning technique.

6 


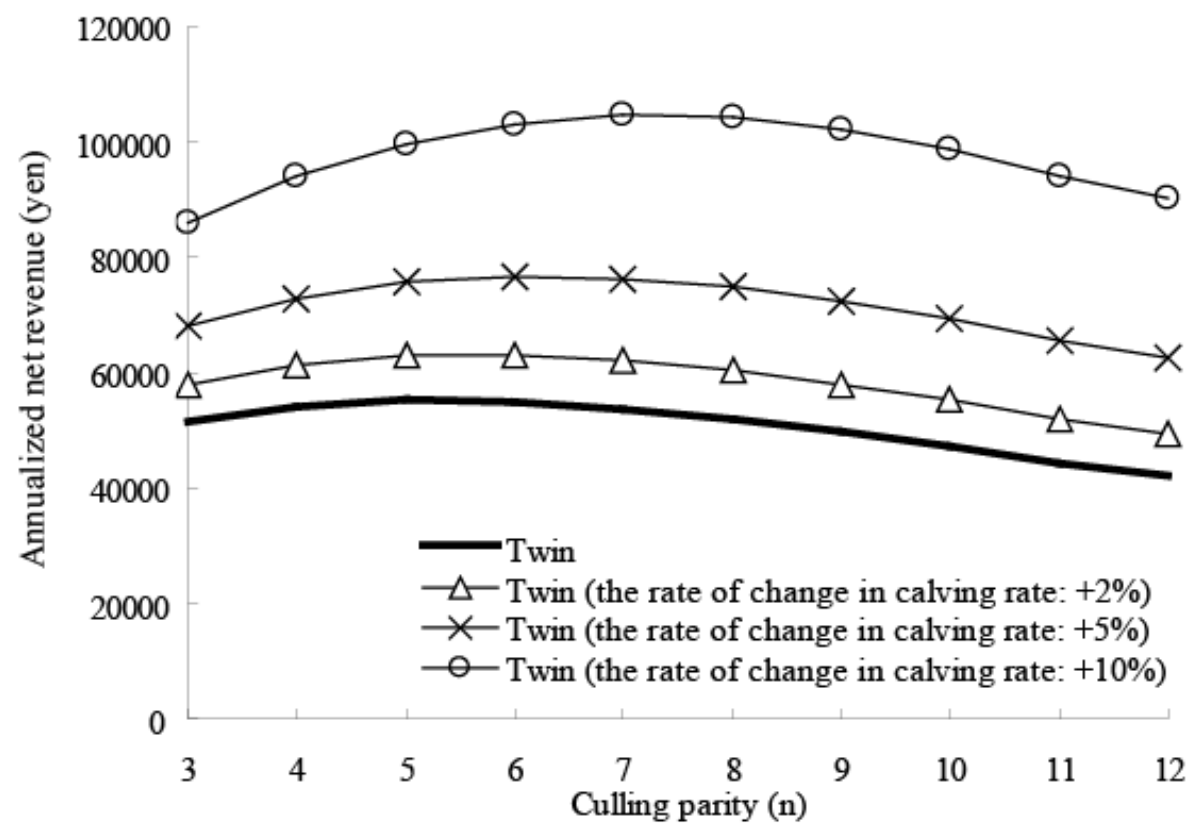

2 Fig. 6. Effects of the change in the rate of change in the calving rate on the annualized

3 net revenue in the production system with the twinning technique.

4

5 